\title{
Textos escolares de ciencias: la transposición didáctića y la lingüística sistemico-funcional del modelo de la doble hélice del ADN ${ }^{1}$
}

\author{
Rosalba Alfonso Sierra ${ }^{2}$ \\ Patricia Gallego Torres ${ }^{3}$ \\ Lorena Martínez Delgado ${ }^{4}$
}

Recibido: 05-07-2016

Aceptado: 07-09-2016

\section{RESUMEN}

El texto escolar es el resultado de los procesos de didactización de los saberes para la escuela moderna, en ellos subyacen prescripciones curriculares, ideologías y discursos; que ejercen control en el proceso de aprendizaje, influyen en el comportamiento de las personas y contribuyen con la calidad de la educación. Con el fin de determinar la comunicación de los saberes en los libros de texto de ciencias naturales de grado noveno, se hizo un análisis de contenido sobre el tema del modelo de la doble hélice del ácido desoxirribonucleico (ADN), en cuanto a contenidos y como estos son expresados, vistos desde las teorías de la Transposición Didáctica (TD) y la Lingüística Sistémico Funcional (LSF). En los tres textos analizados, se hallaron errores de TD respecto al modelo descrito originalmente y en cuanto a la LSF predominan los procesos relacionales sobre los materiales característicos de las ciencias naturales, la mayoría de verbos fueron usados en presente simple, existen metáforas-nominalizaciones; que conllevan a un discurso de

1.Artículo de investigación científica y tecnológica- USTA Doctorado Educación.

2. Bacterióloga, Universidad Colegio Mayor de Cundinamarca; magister Bioquímica, Universidad Nacional de Colombia; especialista en pedagogía, Universidad Pedagógica Nacional; estudiante del Doctorado en Educación, Universidad Santo Tomás; docente de ciencias naturales, Secretaría de Educación de Cundinamarca; e-mail: ciercentrorosalba@gmail.com

3. Licenciada en Física, Universidad Pedagógica Nacional; especialista en Educación Socio Ambiental, Universidad de Valencia; doctorado en Ciencias Físicas Didáctica de las Ciencias; docente del Doctorado Interinstitucional en Educación, Universidad Distrital Francisco José de Caldas; e-mail: patriciagallegot@gmail.com

4. Enfermera, Pontificia Universidad Javeriana; diplomada en Educación para la Salud, Universidad de Valencia, especialista en Docencia Universitaria, Universidad Industrial de Santander; Ph.D. en Educación, Universidad Santo Tomás; docente Enfermería, Pontificia Universidad Javeriana; e-mail: lorenamartinez53@hotmail.com 
ciencia descontextualizada, estática, terminada, que pueden limitar la comprensión del lector y su aprendizaje; por lo que se necesita la intervención del docente para evitar errores en el aprendizaje.

Palabras clave: Texto escolar, modelo de la doble hélice del ADN, transposición didáctica, Lingüística Sistémico-Funcional.

\title{
Scholarly science textbooks: the didactic transposition and systemic-functional linguistics of the DNA double helix model
}

\begin{abstract}
The scholarly text is the result of the processes of teaching knowledge for the modern school in which underlying curricular prescriptions, ideologies and speeches that exert control in the learning process, influence the behavior of people and contribute to the quality of education. In order to determine the communication of knowledge in ninth grade natural science textbooks, a content analysis was undertaken with regard to the double helix of deoxyribonucleic acid (DNA), in terms of contents and how these are expressed in the light of the theories of Didactic Transposition (DT) and Functional Systemic Linguistics (FSL). In the three texts analyzed, DT errors were found with respect to the original model, and as regards LSF, the relative processes predominate over characteristic natural science materials, most verbs were used in simple present, there are metaphors-nominalizations which lead to a discourse of decontextualized, static, finished science that can limit the reader's understanding and learning; So the intervention of the teacher is necessary in order to avoid mistakes in learning.
\end{abstract}

Keywords: School textbook, DNA double helix model, Didactic Transposition, Systemic-Functional Linguistics. 


\section{Introducción}

Los textos escolares de ciencias naturales son herramientas de ayuda para los estudiantes y docentes, han sido elaborados por las editoriales con una propuesta didáctica implícita o explícita; son un referente en la elaboración del proyecto curricular y en su mayoría predominan metodologías expositivas sobre contenidos procedimentales propios de las ciencias naturales; muchos proyectan una imagen de ciencia producto, descontextualizada y ahistórica, presentan actividades e imágenes que poco contribuyen con el desarrollo del pensamiento científico, no tienen en cuenta actividades que indaguen sobre los presaberes de los estudiantes; su lenguaje a veces es complicado y limita la comprensión y comunicación con el lector; es decir, no promueven la verdadera alfabetización científica.

El fin de la educación científica, según Pozo \& Gómez (1998), es "dar sentido al mundo que nos rodea y entender el sentido del conocimiento científico y su evolución" (p. 128), estar alfabetizado científicamente implica comprender las características y las leyes básicas del mundo que nos rodea, los marcos conceptuales para su interpretación, familiarizarse con los modos de hacer ciencia (pensamiento crítico y autónomo, hacer preguntas, interpretar evidencias, construir modelos, argumentar, buscar consensos), sin convertirse en científico; pero sí desarrollando las competencias de lenguaje oral y escrito para apropiarse del conocimiento científico.

El conocimiento del modelo del ADN es importante para entender la ciencia que circula a diario, y frente a la cual se debe tomar posición como en el caso de las nuevas tecnologías, organismos transgénicos, enfermedades genéticas y mutaciones, entre otros, por lo que es necesario que los textos de ciencias naturales aborden actividades que promuevan el desarrollo de competencias científicas en los estudiantes.

Los textos escolares ayudan a orientar la educación, responden a los estándares básicos de educación en ciencias naturales del MEN (Ministerio de Educación Nacional - MEN, 2004), promueven competencias científicas y proponen actividades y estrategias para lograrlas; pero el docente debe seleccionar actividades que le permitan cumplir con los objetivos propuestos; por tanto el texto debe ser comprensible por cuanto en la comunicación de saberes influyen rasgos lingüísticos que producen ciertos efectos en el lector que se pueden analizar a través de 
la teoría Lingüística Sistémico-Funcional (LSF) (Halliday, 1994; Martin \& Rose, 2003; Moss, 2011); un modelo holístico del lenguaje y su contexto social, concebido como recurso para la construcción de significados y el logro de propósitos comunicativos.

Desde la LSF, comprender un texto es ser capaz de comprender los procesos a los que hace referencia, el rol de los participantes y las circunstancias en que se desarrollan los procesos, la función del habla, los tipos de promesas, ofrecimientos, demandas, preguntas, características retóricas que lo constituyen como un acto simbólico, el valor y centralidad del mensaje y coherencia entre sus partes (Halliday \& Hasan, 1991); en el discurso del texto escolar de ciencias naturales existen los roles de escritor y lector, que establecen una interacción pedagógica en un contexto y tiempo dado; el aprendizaje depende de la fluidez de expresión y coherencia de ideas del autor, de la capacidad para interactuar con el lector para cautivar y reconstruir una realidad; de tal forma que el estudiante pueda desaprender y aprender para alcanzar la comprensión de la situación.

La unidad de análisis de la LSF es la cláusula compuesta por los procesos (verbos), participantes (sustantivos) y circunstancias (adverbios); que ordenan el flujo de eventos. La teoría LSF interpreta el lenguaje como recurso semiótico para significar desde diferentes perspectivas complementarias, analiza las metafunciones que combinan tres tipos de significados o metafunciones en el lenguaje de un acto comunicativo, estos son los significados experienciales, interpersonales y textuales (Martin \& White, 2005).

Los significados experienciales se refieren a la construcción de la experiencia (qué ocurre, quién hace qué y a quien, dónde, cuándo, cómo y porqué); son hechos y situaciones reconstruidos mediante un lenguaje comprensible; son 6 tipos de cláusulas según el proceso para reconstruir la realidad (Tabla 1); los sistemas lingüísticos que le dan forma son la transitividad y la ergatividad, la primera son los recursos gramaticales que reflejan e imponen orden a la variación y flujo de eventos, y los interpreta en términos de transmisión. 
Tabla 1. Significados ideacionales: Tipos de cláusula según el proceso.

\begin{tabular}{|l|l|l|}
\hline Cláusulas & Significado & Participantes \\
\hline Material & $\begin{array}{l}\text { Hacer y ocurrir } \\
\text { Crear y transformar }\end{array}$ & Actor, meta, beneficiario, rango \\
\hline Relacional & $\begin{array}{l}\text { Relación entre dos entidades con un } \\
\text { vínculo entre ellas }\end{array}$ & $\begin{array}{l}\text { Portador y atributo } \\
\text { Identificado e identificador }\end{array}$ \\
\hline Mental & Sentir, pensar y percibir & Sensor y fenómeno \\
\hline Verbal & $\begin{array}{l}\text { Intercambio de significados } \\
\text { simbólico: decir y simbolizar }\end{array}$ & $\begin{array}{l}\text { Hablante, receptor, objetivo, } \\
\text { verbalización }\end{array}$ \\
\hline Existencial & Existencia de un fenómeno & Existente \\
\hline Conductual & Conductas psicológicas y fisiológicas & Ser consciente \\
\hline
\end{tabular}

Fuente. Chamorro, 2013.

La ergatividad tiene que ver con la causalidad y agencialidad de la cláusula, si se hace visible el agente causal del proceso es ergativa y cuando permanece implícito es no-ergativa; como en "El ADN se descubrió en 1953"; sugiere que el ADN realiza la acción "descubrir", invisibiliza el agente externo del proceso; mientras que "Los científicos descubrieron el ADN en 1953"; es ergativa. Cuando los textos de ciencias naturales abordan los procesos con abundantes cláusulas no-ergativas, se asocia a la presentación de las actividades humanas como circunstancias y no como agencias; esto conlleva a diluir la responsabilidad del individuo en la situación.

Los significados interpersonales, son las relaciones sociales generadas cuando interactúan las personas y comparten puntos de vista y sentires a través del texto, el lector se relaciona con posiciones, actitudes, juicios y voces que se vislumbran a partir de él (Chamorro, 2013); según Halliday (2004) "el lenguaje construye el discurso como un evento interactivo, asignando un rol para el hablante o escritor, y uno para la audiencia o lector"; esta interacción permite el intercambio de bienes y servicios a través de ofrecimientos, dar información mediante afirmaciones, solicitar bienes o servicios en forma de órdenes, o solicitar información mediante preguntas; por tanto, se espera una respuesta del lector. Por ejemplo, ¿podrían responder estas preguntas rápidamente? (Chamorro, 2013).

Los significados textuales es la forma como está organizado el texto como un mensaje coherente. La gramática junto al vocabulario técnico hacen que la comprensión del discurso científico comporte cierto nivel de complejidad, existen siete rasgos de la complejidad en los textos de 
ciencias: definiciones entrelazadas (usar términos acabados de definir para un nuevo concepto), taxonomías técnicas (organizar los términos por categorías), expresiones especiales, densidad léxica, ambigüedad sintáctica, discontinuidad semántica (saltos semánticos que el lector no puede seguir) y metáfora gramatical; las cinco últimas, propias de la evolución de la ciencia (Halliday, 1993).

El lenguaje científico usa abstracciones, generalizaciones y metáforas para referirse a fenómenos; la metáfora gramatical es el cambio de una clase gramatical o estructura por otra; la más común es la nominalización; cuando se alude a procesos y propiedades en forma de sustantivos en vez de verbos y adjetivos; "para mantener inmóvil la realidad para permitir la observación y experimentación" (citado por Chamorro, 2013); los procesos y propiedades objetivizados se presentan como acabados, indiscutibles, incambiables y deben ser aceptados por el lector como realidad; muestran estructuras compactas, eliminan información que se supone conocida, permiten avanzar en la argumentación y explicación; aunque en lectores menos expertos como los estudiantes se convierten en obstáculo para la comprensión (Chamorro, 2013).

Otra característica del discurso científico es el uso del tiempo presente simple verbal para hacer referencia a leyes universales o generales y normas, por ejemplo "los gases adquieren la forma del recipiente que los contiene y tienden a ocupar el mayor volumen posible" (Manjarrés \& Chamorro, 2011, p. 135); su uso no deja la posibilidad de avances, cambios o refutaciones futuras.

El conocimiento científico es producido por grupos especializados, para que pueda ser llevado a las aulas debe ser objeto de una transformación y adecuación para ser enseñado, este proceso es denominado TD descrita por Chevallard (1991) como "el trabajo que transforma de un objeto de saber a enseñar en un objeto de enseñanza" (p. 45). La TD debe incluir en los textos la formación conceptual propia de la disciplina, los métodos y valores propios de la actividad científica, las explicaciones que desde la historia y la filosofía han sido realizadas, relacionándolas con la naturaleza de la ciencia y la construcción y evolución del conocimiento científico, para entender el camino recorrido por cada disciplina que tuvo su origen en la cultura y no un hallazgo al azar o un descubrimiento.

La TD es necesaria porque los conocimientos científicos no pueden ser enseñados directamente en la escuela, requieren de un proceso de 
adaptación de un "saber sabio" generado en grupos especializados, a "saber para ser enseñado" plasmado en textos y luego en "saber enseñado" cuando es llevado al aula; participan científicos, comunidad, comunidad científica, sociedad, editoriales, instituciones gubernamentales y profesores; quienes interpretan y seleccionan qué contenido enseñar, la finalidad, la forma, el nivel a quien va dirigido; para presentarlo de manera accesible, contextualizada y adecuada al nivel académico. El proceso puede introducir tergiversaciones o errores conceptuales; en los textos usados como guía del docente, organizador curricular, planificador, generador de secuencias de aprendizaje, preparador de clase, fuente de talleres y prácticas de laboratorio, herramienta de consulta de los estudiantes; es decir, la TD en un texto requiere unos mínimos para educar científicamente.

Los problemas de TD detectados en textos de ciencias naturales están relacionados con ausencia del manejo de conceptos básicos y falta de consenso entre autores (Chamizo \& Gutiérrez, 2004), proposiciones erróneas, generalizadas, omisiones que favorecen la generación de concepciones alternativas (Raviolo, 2008; Pérez, Álvarez, \& Serrallé, 2009; Herreño, Gallego, \& Pérez, 2010; Raviolo, 2009); múltiples definiciones con predominio reduccionista y desactualización (Bermúdez, 2014), falta de correspondencia con las referencias citadas (Franzolin \& Bizzo, 2015); carencia de actividades dirigidas a indagar sobre los conceptos alternativos y de tareas para comprobar los aprendizajes (Totorikaguena, 2013). Esta problemática conduce a aprendizajes superficiales, insuficientes, heterogéneos, pasajeros y erróneos que aumentan las concepciones alternativas y dificultan los procesos de formación.

Otra dificultad es la descontextualización del tema en tiempo y espacio, transmite una versión de ciencia producto (Gallego, Gallego \& Pérez, 2010), que no corresponde a una construcción social; presenta explicaciones sin profundidad en elementos básicos que sirvieron para la construcción del modelo y desconocimiento de los principios históricos y epistemológicos relevantes de la historia y la filosofía de la ciencia (Gallego, Gallego \& Pérez, 2010); una visión de ciencia experimentalista, empírico positivista con una versión situada en el siglo pasado (López, 2012) y rasgos discursivos que dificultan la comprensión (Moss, Natale, \& Oteiza, 2009); afectando el proceso de aprendizaje.

Un gran avance de la ciencia ocurrió en 1953, cuando en la revista Nature, Watson y Crick publicaron la propuesta del modelo de la doble hélice 
del ADN, formado por dos cadenas antiparalelas, enrolladas en espiral, constituidas por un esqueleto de grupos fosfato y desorribosa; que en su interior albergaba las bases nitrogenadas unidas por puentes de hidrógeno; en cada vuelta de espiral 10 pares de bases, enfrentadas la A:T y G:C (Adenina, Timina, Guanina y Citocina), mostrando un modelo diferente de la estructura previa de 3 hélices propuesta por Pauling y Corey (1953); y además, el diagrama de Rayos X corroboraba lo expuesto (Watson \& Crick, 1953).

El modelo de la doble hélice del ADN es el resultado del conocimiento científico acumulado, ha servido a otros investigadores para obtener nuevos hallazgos y corroborar aspectos del modelo propuesto en 1953, por lo que este modelo es un buen ejemplo de la actividad científica como una construcción colectiva que marcó el nacimiento de la biología molecular y significó un gran avance en la investigación biológica. Los principales trabajos que aportaron a éste modelo de la doble hélice del ADN fueron los siguientes:

En 1865 Gregorio Mendel, demostró que existían rasgos que se transmitían de padres a hijos, hoy conocidos como genes (Mendel, 1866); a finales 1920, Frederick Griffith, halló el principio transformador (Griffith, 1928); luego conocido como ADN. Posteriormente en los trabajos con bacteriófagos concluyeron que el ADN era la molécula de la herencia (Hershey \& Chase, 1952); los estudios de difracción de rayos X permitieron confirmar la propuesta teórica del modelo de la doble hélice del ADN (Franklin, 1953); y la ley de Chargaff demostró que la cantidad de Adenina (A) es igual a la de Timina (T), y la de Guanina (G) a la de Citosina(C) (Chargaff, 1951).

\section{Metodología}

Para identificar los libros de ciencias naturales más usados, se realizó una encuesta a 10 profesores de diferentes instituciones educativas de la que se obtuvieron dos libros: Avanza Ciencias 9 de editorial Norma, 2014 e Hipertexto Santillana Ciencias 9, 2010; (los textos más recomendados a estudiantes de instituciones públicas de la región de Oriente de Cundinamarca) y el tercer texto Biología la vida en la tierra de editorial Pearson, 2008, texto guía del colegio Ciudadela Colsubsidio de Bogotá. 
Estos tres textos fueron evaluados mediante lectura directa de los contenidos sobre el modelo de la hélice del ADN. Así mismo, se analizó su contenido desde las teorías LSF con el fin de determinar la capacidad de comunicación del texto y de la TD, para determinar la calidad de sus saberes. Se hizo lectura directa y tabulación de la metafunción experiencial del lenguaje, se tipificaron y tabularon las cláusulas de cada párrafo, se evaluaron los tiempos verbales usados, metáforas y nominalizaciones; y mediante búsqueda bibliográfica de artículos de ciencias naturales relacionados con la TD se establecieron los parámetros críticos a evaluar en los textos.

Para el análisis, primero se obtuvieron los párrafos y sus cláusulas, se tabularon y tipificaron de acuerdo a la metafunción experiencial de la tabla 1. Luego, se determinó la ergatividad de las cláusulas materiales; los datos obtenidos fueron tabulados, el análisis de un párrafo se muestra en la tabla 2 donde la letra cursiva denota los verbos (procesos) analizados en la metafunción experiencial, luego el uso del lenguaje verbal y en la última casilla aparecen las nominalizaciones.

\section{Resultados}

En los datos obtenidos del análisis de la metafunción experiencial es de notar que en todos los textos más de la mitad de los procesos de la metafunción experiencial son relacionales, mientras que los procesos materiales importantes en las ciencias naturales son solo $1 / 6$ aproximadamente; y los procesos mentales importantes desde el punto de vista de comunicación porque reflejan seres dotados de conciencia, se presentan en muy baja cantidad excepto en la Biología la vida en la tierra (tabla 3). En cuanto a la ergatividad de los procesos en los textos analizados, se observa que los procesos materiales ergativos están en menor proporción que los no-ergativos, por lo que no hay una agencialidad del proceso y su responsabilidad está diluida. 
Tabla 2. Análisis de la metafunción experiencial, tiempos verbales y metáforas.

\begin{tabular}{|c|c|c|c|}
\hline $\begin{array}{l}\text { Avanza Ciencias 9. Norma. } 2014 . \\
\text { Página 13. Párrafo } 2\end{array}$ & $\begin{array}{l}\text { Metafunción } \\
\text { experiencial } \\
\text { (ergativa / no- } \\
\text { ergativa) }\end{array}$ & $\begin{array}{l}\text { Lenguaje de } \\
\text { la ciencia - } \\
\text { verbos }\end{array}$ & Nominalizaciones \\
\hline $\begin{array}{l}\text { La estructura del ADN } \\
\text { Los ácidos nucleicos se encuentran } \\
\text { dentro de las células. } \\
\text { El ADN se localiza dentro de } \\
\text { estructuras llamadas cromosomas, } \\
\text { en el núcleo de las células. } \\
\text { Los cromosomas están compuestos } \\
\text { por proteínas y ADN, que es } \\
\text { la molécula portadora de la } \\
\text { información genética del organismo. } \\
\text { Para determinar la composición } \\
\text { química del ADN fueron necesarios } \\
\text { muchos años de investigaciones y } \\
\text { experimentos. } \\
\text { El resultado fue el modelo propuesto } \\
\text { por James Watson y Francis Crick } \\
\text { en } 1953 \text {, que sigue siendo aceptado } \\
\text { en la actualidad. } \\
\text { Por este trabajo ambos científicos } \\
\text { recibieron el Premio Nobel de } \\
\text { Medicina en } 1962 \text {. }\end{array}$ & $\begin{array}{l}\text { Proceso existencial } \\
\text { Proceso relacional } \\
\text { Proceso relacional } \\
\text { Proceso relacional } \\
\text { Proceso relacional } \\
\text { Proceso relacional } \\
\text { Proceso relacional } \\
\text { Proceso relacional } \\
\text { Proceso material / } \\
\text { ergativo }\end{array}$ & $\begin{array}{l}\text { encuentran: } \\
\text { presente } \\
\text { localiza: } \\
\text { presente } \\
\text { están: } \\
\text { presente } \\
\text { es: } \\
\text { presente } \\
\text { determinar: } \\
\text { Infinitivo } \\
\text { fueron: } \\
\text { pasado } \\
\text { fue: } \\
\text { pasado } \\
\text { sigue siendo: } \\
\text { presente } \\
\text { progresivo } \\
\text { recibieron: } \\
\text { pasado }\end{array}$ & $\begin{array}{l}\text { Para determinar ... } \\
\text { El resultado ... } \\
\text { Son } \\
\text { nominalizaciones, } \\
\text { usan verbos } \\
\text { objetivizados, se } \\
\text { requiere reconstruir } \\
\text { el agente que realiza } \\
\text { el proceso. }\end{array}$ \\
\hline $\begin{array}{l}\text { Hipertexto Santillana Ciencias } 9 . \\
\text { 2010. Página 10. Párrafo } 1\end{array}$ & $\begin{array}{l}\text { Metafunción } \\
\text { experiencial } \\
\text { (ergativa / no- } \\
\text { ergativa) }\end{array}$ & $\begin{array}{l}\text { Lenguaje de } \\
\text { la ciencia - } \\
\text { verbos }\end{array}$ & Nominalizaciones \\
\hline $\begin{array}{l}\text { Los ácidos nucleicos } \\
\text { La identidad de los "factores } \\
\text { hereditarios" de Mendel comenzó } \\
\text { a conocerse cuando en 1869, el } \\
\text { biólogo suizo Johan Friedrich } \\
\text { Miescher (1844-1895) aisló, del } \\
\text { núcleo de los glóbulos blancos, } \\
\text { unas moléculas a las que llamó } \\
\text { nucleinas. } \\
\text { Estas nucleinas estaban formadas } \\
\text { por carbono, nitrógeno, oxígeno, } \\
\text { nitrógeno y gran cantidad de fósforo. } \\
\text { Posteriormente, se encontró que } \\
\text { este compuesto estaba formado por } \\
\text { un componente de tipo proteico y } \\
\text { otro de carácter ácido, por lo que } \\
\text { las nucleinas comenzaron a ser } \\
\text { llamadas ácidos nucleicos. }\end{array}$ & $\begin{array}{l}\text { Proceso relacional } \\
\text { Proceso material, } \\
\text { ergativo } \\
\text { Proceso verbal } \\
\text { Proceso relacional } \\
\text { Proceso material, } \\
\text { no-ergativo } \\
\text { Proceso relacional } \\
\text { Proceso relacional } \\
\text { Proceso relacional }\end{array}$ & $\begin{array}{l}\text { comenzó: } \\
\text { pasado } \\
\text { aisló: } \\
\text { pasado } \\
\text { llamó: } \\
\text { pasado } \\
\text { estaban: } \\
\text { pasado } \\
\text { encontró: } \\
\text { pasado } \\
\text { estaba: } \\
\text { pasado } \\
\text { comenzaron: } \\
\text { pasado } \\
\text { ser llamadas: } \\
\text { infinitivo }\end{array}$ & $\begin{array}{l}\text { Posteriormente, se } \\
\text { encontró... } \\
\text { Es una } \\
\text { nominalización, } \\
\text { el portador } \\
\text { reemplazado por un } \\
\text { adverbio. }\end{array}$ \\
\hline
\end{tabular}




\begin{tabular}{|c|c|c|c|}
\hline $\begin{array}{l}\text { Biología La vida en la tierra. } \\
\text { Pearson. 2008. Página } 151 . \\
\text { Párrafo } 1\end{array}$ & $\begin{array}{l}\text { Metafunción } \\
\text { experiencial } \\
\text { (ergativa / no- } \\
\text { ergativa) }\end{array}$ & $\begin{array}{l}\text { Lenguaje de } \\
\text { la ciencia - } \\
\text { verbos }\end{array}$ & Nominalizaciones \\
\hline $\begin{array}{l}\text { ¿Cuál es la estructura del DNA? } \\
\text { El hecho de saber que los genes } \\
\text { están hechos de DNA no responde } \\
\text { las preguntas fundamentales acerca } \\
\text { de la herencia: } \\
\text { ¿Cómo codifica el DNA la } \\
\text { información genética? } \\
\text { ¿Cómo se duplica el DNA de } \\
\text { manera que la información pueda } \\
\text { ser transferida con exactitud de } \\
\text { una célula madre a las células } \\
\text { hijas? (Véase el capítulo } 11 \text { para } \\
\text { mayor información acerca de la } \\
\text { reproducción celular). } \\
\text { Los secretos de la función del DNA } \\
\text { y, por consiguiente, de la herencia } \\
\text { misma, sólo se descubrieron } \\
\text { cuando se comprendió la estructura } \\
\text { tridimensional de la molécula de } \\
\text { DNA. }\end{array}$ & $\begin{array}{l}\text { Proceso relacional } \\
\text { Proceso verbal } \\
\text { Proceso relacional } \\
\text { Proceso relacional } \\
\text { Proceso relacional } \\
\text { Proceso mental } \\
\text { Proceso material no- } \\
\text { ergativo } \\
\text { Proceso mental }\end{array}$ & $\begin{array}{l}\text { están: } \\
\text { presente } \\
\text { responde: } \\
\text { presente } \\
\text { codifica: } \\
\text { presente } \\
\text { duplica: } \\
\text { presente } \\
\text { ser: } \\
\text { infinitivo } \\
\text { véase: } \\
\text { imperativo } \\
\text { descubrieron: } \\
\text { pasado } \\
\text { comprendió: } \\
\text { pasado }\end{array}$ & $\begin{array}{l}\text { Los secretos de la } \\
\text { función del DNA ... } \\
\text { Es nominalización, } \\
\text { la agenciabilidad es } \\
\text { atribuida a moléculas } \\
\text { de ADN y son los } \\
\text { humanos los que } \\
\text { descubrieron la } \\
\text { función del ADN. }\end{array}$ \\
\hline
\end{tabular}

Tabla 3. Resultados del análisis de la Metafunción experiencial.

\begin{tabular}{|l|l|l|l|}
\hline $\begin{array}{l}\text { Metafunción experiencial } \\
\text { Procesos/Texto }\end{array}$ & $\begin{array}{l}\text { Avanza } \\
\text { Ciencias 9 }\end{array}$ & $\begin{array}{l}\text { Hipertexto } \\
\text { Santillana } \\
\text { Ciencias 9 }\end{array}$ & $\begin{array}{l}\text { Biología la vida en } \\
\text { la tierra }\end{array}$ \\
\hline Relacional & $15(51,7 \%)$ & $48(69,6 \%)$ & $109(69,4 \%)$ \\
Material ergativo & $3(10,3 \%)$ & $8(11,6 \%)$ & $7(4,5 \%)$ \\
Material no-ergativo & $2(6,8 \%)$ & $8(11,6 \%)$ & $18(11,5 \%)$ \\
Mental & $1(3,4 \%)$ & $1(1,5 \%)$ & $15(9,5 \%)$ \\
Verbal & - & $1(1,5 \%)$ & $5(3,2 \%)$ \\
Existencial & $8(27,5 \%)$ & $1(1,5 \%)$ & $3(1,9 \%)$ \\
Conductual & - & $2(3 \%)$ & - \\
Total & $29(100 \%)$ & $69(100 \%)$ & $157(100 \%)$ \\
\hline
\end{tabular}

Muchas veces la dificultad en la comprensión del texto escolar se debe al lenguaje utilizado en su comunicación como a los tiempos verbales. Cuando un discurso se puede ubicar temporalmente, facilita la contextualización y comprensión, aunque no es típico del discurso de las ciencias naturales que utilizan más el tiempo presente, pero si es necesario cuando se usa para fines didácticos; es de notar que más del $60 \%$ de los verbos utilizados para comunicar el modelo de la doble hélice del DNA en los textos Avanza Ciencias g e Hipertexto Santillana Ciencias 9 están en tiempo presente, mientras que en el texto de Biología de la vida el tiempo verbal mayoritario es el pasado (ver tabla 2 segunda columna y tabla 4 ). 
Tabla 4. Tiempos verbales utilizados en el discurso textual.

\begin{tabular}{|l|l|l|l|}
\hline Tiempo verbal / Texto & $\begin{array}{l}\text { Avanza } \\
\text { Ciencias 9 }\end{array}$ & $\begin{array}{l}\text { Hipertexto } \\
\text { Santillana } \\
\text { Ciencias 9 }\end{array}$ & $\begin{array}{l}\text { Biología la vida en } \\
\text { la tierra }\end{array}$ \\
\hline $\begin{array}{l}\text { Presente simple } \\
\text { Infinitivo }\end{array}$ & $25(73.5 \%)$ & $43(62.3 \%)$ & $66(41.8 \%)$ \\
Participio pasado & $2(5.9 \%)$ & $9(13.4 \%)$ & $9(5.7 \%)$ \\
Gerundio & - & $1(1.4 \%)$ & - \\
Pasado & $1(2.9 \%)$ & $1(1.4 \%)$ & - \\
Futuro & $5(14.7 \%)$ & $13(18.8 \%)$ & $79(50 \%)$ \\
TOTAL & $1(2.9 \%)$ & $2(2.8 \%)$ & $4(2.5 \%)$ \\
\hline
\end{tabular}

Los textos de ciencias naturales utilizan frecuentemente el lenguaje metafórico, en el cual la realidad es expresada con otra realidad diferente pero que guardan ciertas relaciones de semejanza, para comprender mejor lo que ocurre alrededor; las nominalizaciones son consideradas metáforas y son muy frecuentes en el lenguaje de los textos de ciencias naturales (Tabla 2 última columna y tabla $5 \mathrm{~A}$ y $5 \mathrm{~B}$ ).

Tabla 5. Metáforas halladas en los textos: A, ejemplos y B, tabulaciones.

A \begin{tabular}{|l|l|}
\hline Avanza Ciencias 9 & Párrafo \\
\hline ... la molécula de ADN consta de dos largas hebras enrolladas en forma de hélice. & 3 \\
\hline Cada hebra es una cadena de bloques llamados nucleótidos. & 3 \\
\hline ... que se enrollan en espiral, formando una especie de escalera en caracol. & 4 \\
\hline La unión de los peldaños a lado y lado de la molécula está formada ... & 5 \\
\hline Hipertexto Santillana Ciencias & Párrafo \\
\hline $\begin{array}{l}\text { La causa de estas características visibles era la existencia de lo que denominó } \\
\text { "factores hereditarios". }\end{array}$ & 1 \\
\hline $\begin{array}{l}\text { Estos son moléculas que como verás, son decisivas en el proceso de la } \\
\text { transmisión de la información hereditaria. }\end{array}$ & 1 \\
\hline Las bases nitrogenadas son moléculas en forma de anillo & \\
\hline Biología la vida en la tierra & 4 \\
\hline $\begin{array}{l}\text { Como la doble hélice sólo tiene pares A-T y G-C, todos los peldaños de la } \\
\text { escalera del DNA tienen el mismo ancho. }\end{array}$ & 14 \\
\hline $\begin{array}{l}\text { Francis Crick proclamó ante los comensales: "Hemos descubierto el secreto de la } \\
\text { vida". }\end{array}$ & 14 \\
\hline
\end{tabular}

B

\begin{tabular}{|l|l|l|l|}
\hline Tipos/ Texto & $\begin{array}{l}\text { Avanza } \\
\text { Ciencias 9 }\end{array}$ & $\begin{array}{l}\text { Hipertexto } \\
\text { Santillana } \\
\text { Ciencias 9 }\end{array}$ & $\begin{array}{l}\text { Biología la vida en } \\
\text { la tierra }\end{array}$ \\
\hline Metáforas & 16 & 11 & 58 \\
Nominalizaciones & 5 & 11 & 10 \\
TOTAL & 8 & 22 & 12 \\
\hline
\end{tabular}


En la LSF es importante la comunicación establecida en el texto con el lector a través de diferentes expresiones o solicitudes que lo ayudan a contextualizar el tema y a comprenderlo mejor, la comunicación en los textos analizados tiene formas verbales o pronominales en segunda persona del singular "tu" o imperativos que denotan confianza cuya intención es acercar, contextualizar, conectar y mantener motivado al lector (tabla 6); aunque no es una regularidad. En los textos Avanza Ciencias 9 y el Hipertexto Santillana Ciencias 9, en la introducción hay invitaciones directas, ordenes, preguntas que solicitan acciones o inducen al lector a reflexionar sobre acciones cotidianas; en la Biología la vida en la tierra, se aprecia un interés del autor por mantener la conexión del lector con los temas anteriores, por establecer los roles e indicar qué espera del lector e informarle sobre lo que se va a tratar.

Tabla 6. Evidencia de la interacción establecida entre el texto y el lector.

\begin{tabular}{|c|c|c|c|}
\hline $\begin{array}{l}\text { Solicitud al } \\
\text { lector }\end{array}$ & $\begin{array}{l}\text { Avanza } \\
\text { Ciencias } 9\end{array}$ & $\begin{array}{l}\text { Hipertexto Santillana } \\
\text { Ciencias } 9\end{array}$ & $\begin{array}{l}\text { Biología la vida en la } \\
\text { tierra }\end{array}$ \\
\hline $\begin{array}{l}\text { Introducción } \\
\text { del capítulo }\end{array}$ & $\begin{array}{l}\text { Consume alimentos eco } \\
\text { amigable libres de OMG. } \\
\text { ¿A quiénes } \\
\text { recomendarías comprar el } \\
\text { alimento que observas ... }\end{array}$ & $\begin{array}{l}\text { El uso de alimentos } \\
\text { fortificados... ¿Crees que } \\
\text { puede ser una solución } \\
\text { para el futuro? Argumenta } \\
\text { tu respuesta. } \\
\text { En qué consiste tu } \\
\text { alimentación diaria? } \\
\text { ¿Qué efectos crees } \\
\text { que puede tener en la } \\
\text { salud...? }\end{array}$ & $\begin{array}{l}\text {...evidencia de que los } \\
\text { genes son parte de los } \\
\text { cromosomas (véase los } \\
\text { capítulos } 5,11 \text { y } 12 \text { ). } \\
\text { Véase el capítulo } 11 \text { para } \\
\text { mayor información... }\end{array}$ \\
\hline Presaberes & $\begin{array}{l}\text { Muchos de los rasgos } \\
\text { físicos tuyos son iguales } \\
\text { o similares a los de } \\
\text { tu mamá o tu papa e } \\
\text { inclusive a los de tus } \\
\text { abuelos y abuelas. } \\
\text { ¿Cómo crees que se } \\
\text { transmiten estos rasgos } \\
\text { físicos de generación en } \\
\text { generación? }\end{array}$ & No se observa & No se observa \\
\hline $\begin{array}{l}\text { En el cuerpo } \\
\text { del texto }\end{array}$ & No se observa & No se observa & $\begin{array}{l}\text { ¿Qué crees que sería } \\
\text { más difícil de romper: un } \\
\text { par de Bases A-T o un par } \\
\text { de bases C-G? } \\
\text { Quizá ahora estés } \\
\text { pensando: "Un momento, } \\
\text { esto no es justo... } \\
\text { Observa de nuevo la } \\
\text { estructura del DNA que se } \\
\text { muestra en la figura 9-5. }\end{array}$ \\
\hline
\end{tabular}




\begin{tabular}{|c|c|c|c|}
\hline & $\begin{array}{l}\text { Avanza } \\
\text { Ciencias } 9\end{array}$ & $\begin{array}{l}\text { Hipertexto Santillana } \\
\text { Ciencias } 9\end{array}$ & $\begin{array}{l}\text { Biología la vida en la } \\
\text { tierra }\end{array}$ \\
\hline \multicolumn{4}{|c|}{ En estructuras auxiliares: } \\
\hline Identificar & $\begin{array}{l}\text { Completa el siguiente } \\
\text { cuadro de las } \\
\text { características del ADN. } \\
\text { Identifica la estructura de } \\
\text { las bases nitrogenadas } \\
\text { que conforman el ADN. }\end{array}$ & $\begin{array}{l}\text { En esta práctica realizarás } \\
\text { observaciones... } \\
\text { Selecciona la muestra... } \\
\text { pélala y córtala en } \\
\text { cuadritos. Mézclala } \\
\ldots \text { prepara... agrega... } \\
\text { mézclala... coloca... } \\
\text { retira... filtra... registra... } \\
\text { observa... introduce... } \\
\text { repite... }\end{array}$ & $\begin{array}{l}\text { Dibuja la estructura } \\
\text { Menciona los cuatro tipos } \\
\text { de bases... } \\
\text { Describe el proceso... }\end{array}$ \\
\hline Analizar & $\begin{array}{l}\text { Lee y responde las } \\
\text { siguientes preguntas. } \\
\text { Observa y analizalas } \\
\text { estructuras del lado } \\
\text { izquierdo... y respondes... } \\
\text { Escribe la secuencia ... }\end{array}$ & $\begin{array}{l}\text { Para construir tu } \\
\text { hipótesis... } \\
\text { Escribe tus hipótesis ... } \\
\text { Compara los resultados ... } \\
\text { Que semejanzas y } \\
\text { diferencias encuentras ... }\end{array}$ & $\begin{array}{l}\text { ¿Piensas que la } \\
\text { secuencia de nucleótidos } \\
\text { de la otra cadena de la } \\
\text { doble hélice también } \\
\text { codifica información útil? }\end{array}$ \\
\hline Opinar & $\begin{array}{l}\text { Solicita a un compañero } \\
\text { que lea... luego } \\
\text { pregúntale qué opina ... }\end{array}$ & $\begin{array}{l}\text { ¿Qué función crees que } \\
\text { cumple..? } \\
\text { ¿Comprobaste tu } \\
\text { hipótesis? } \\
\text { ¿Estás de acuerdo...? }\end{array}$ & $\begin{array}{l}\text { Como viste en la sección } \\
\text { de "Investigación } \\
\text { científica... } \\
\text { ¿Piensas que esta } \\
\text { competencia ayuda } \\
\text { a fomentar los } \\
\text { descubrimientos... } \\
\text { ¿Por qué piensas que } \\
\text { el DNA tiene cadenas } \\
\text { dobles? }\end{array}$ \\
\hline Argumentar & $\begin{array}{l}\text { Comparte la información } \\
\text { de un compañero y } \\
\text { justifica tu respuesta. }\end{array}$ & $\begin{array}{l}\text { Reconozca la importancia } \\
\text { del modelo ... } \\
\text { Diseñen y propongan ... } \\
\text { Elabora un escrito ... en el } \\
\text { que expliques ... }\end{array}$ & $\begin{array}{l}\text { ¿consideras que existen } \\
\text { límites en cuanto al } \\
\text { conocimiento que las } \\
\text { personas deberían } \\
\text { adquirir? Defiende tu } \\
\text { respuesta. }\end{array}$ \\
\hline
\end{tabular}

El texto Avanza Ciencias 9 presenta una pregunta intencionada para explorar presaberes, contextualizar al estudiante y sacar a flote los conocimientos previos (tabla 6). Por otra parte, en el cuerpo del contenido, los dos primeros textos tienen una técnica totalmente expositiva sin evidenciar una interacción con el lector (tabla 6), mientras que en la Biología de la vida en la tierra sigue utilizando una referenciación a apartados previos, además, llama la atención que en todo el texto desarrolla el tema planteando preguntas que no son directas al lector, sino que el mismo autor se responde a manera de monólogo; volviéndolo más narrativo; por ejemplo "¿Cómo descubrieron los científicos que 
los genes están compuestos de DNA?", "Una de estas sustancias debe contener el plano hereditario de la célula, ¿pero cuál?".

Por otra parte, en las estructuras auxiliares que corresponden al desarrollo de actividades, cuestionarios, evaluación de competencias, lecturas auxiliares (tabla 6); el autor invita al lector a través de preguntas dirigidas a identificar, analizar, opinar y argumentar sobre el tema tratado; y es evidente la comunicación directa autor-lector en los tres textos analizados.

Tabla 7. Problemas frecuentes en la TD de textos de ciencias naturales.

\begin{tabular}{|l|l|l|}
\hline Código & Problema & \\
\hline 1 & Ausencia de manejo de conceptos básicos & Chamizo y Gutiérrez, 2004 \\
\hline 2 & Diversidad de afirmaciones sobre el mismo tema & Raviolo,2008 \\
\hline 3 & $\begin{array}{l}\text { Proposiciones erróneas o generalizadas e } \\
\text { imprecisiones }\end{array}$ & Raviolo,2008 \\
\hline 4 & $\begin{array}{l}\text { Multiplicidad de definiciones con predominio } \\
\text { reduccionista }\end{array}$ & Bermúdez, 2014 \\
\hline 5 & $\begin{array}{l}\text { No correspondencia de referencias con conceptos } \\
\text { figuras }\end{array}$ & Franzolina y Bizzo, 2014 \\
\hline 6 & Descontextualización del tema & Herreño, Gallego y Pérez, 2010 \\
\hline 7 & $\begin{array}{l}\text { Ciencia producto no corresponde con una } \\
\text { construcción social }\end{array}$ & Gallego, Gallego y Pérez, 2013 \\
\hline 8 & $\begin{array}{l}\text { Rasgos discursivos que causan dificultad en la } \\
\text { comprensión }\end{array}$ & Moss, 2009 \\
\hline 9 & Conceptos ahistóricos & López, 2012 \\
\hline 10 & Omisiones & Pérez, et al., 2009 \\
\hline 11 & No incluyen actividades para sacar presaberes & Totorikaguena, 2013 \\
\hline 12 & No dejan tareas para comprobar los aprendizajes & Totorikaguena, 2013 \\
\hline
\end{tabular}

Fuente. Elaboración propia.

Una buena TD en los textos escolares previene y corrige problemas asociados a errores conceptuales del aprendizaje. Se hizo una revisión bibliográfica de los artículos publicados con problemas en la TD en textos de ciencias naturales y se codificaron (tabla 7); los cuales sirvieron como parámetro de búsqueda de problemas similares en los textos analizados. 
Tabla 8. Problemas de los textos asociados a la transposición didáctica.

\begin{tabular}{|c|c|c|}
\hline Avanza Ciencias 9. Párrafo 2 & Problema de TD & Código \\
\hline $\begin{array}{l}\text { Los ácidos nucleicos se encuentran dentro } \\
\text { de las células. EI ADN se localiza dentro } \\
\text { de estructuras llamadas cromosomas, en } \\
\text { el núcleo de las células. Los cromosomas } \\
\text { están compuestos por proteínas y } \\
\text { ADN, que es la molécula portadora de } \\
\text { la información genética del organismo. } \\
\text { Para determinar la composición química } \\
\text { del ADN fueron necesarios muchos } \\
\text { años de investigaciones y experimentos. } \\
\text { El resultado fue el modelo propuesto } \\
\text { por James Watson y Francis Crick en } \\
1953 \text {, que sigue siendo aceptado en } \\
\text { la actualidad. Por este trabajo ambos } \\
\text { científicos recibieron el Premio Nobel de } \\
\text { Medicina en } 1962 .\end{array}$ & $\begin{array}{l}\text {... en el núcleo de las células: } \\
\text { Generalización. Solo en eucariotas, los } \\
\text { procariotas no tienen núcleo como tal. } \\
\text { Para determinar la composición química... } \\
\text { El resultado fue el modelo... } \\
\text { La composición química del ADN ya } \\
\text { se conocía. Lo que buscaban era la } \\
\text { estructura. } \\
\text { Reconoce autores del modelo pero no } \\
\text { muestra el aporte de otros alrededor del } \\
\text { mismo modelo. }\end{array}$ & 7 \\
\hline $\begin{array}{l}\text { Hipertexto Santillana Ciencias } 9 . \\
\text { Párrafo } 2\end{array}$ & Problema de TD & Código \\
\hline $\begin{array}{l}\text { La información hereditaria } \\
\text { La información hereditaria es toda } \\
\text { aquella que se requiere para "fabricar" } \\
\text { un organismo. Para Gregorio Mendel, } \\
\text { padre de la genética, la transmisión de } \\
\text { información de los padres, a hijos era } \\
\text { evidente gracias a los rasgos paternos que } \\
\text { se podian observar en las generaciones } \\
\text { posteriores, como por ejemplo el color } \\
\text { de las semillas o de las flores. La causa } \\
\text { de estas características visibles era la } \\
\text { existencia de lo que denominó "factores } \\
\text { hereditarios"... }\end{array}$ & $\begin{array}{l}\text {...fabricar" un organismo. Es una } \\
\text { proposición errónea, a la fecha eso aún no } \\
\text { es posible. } \\
\text { Mendel no fue ubicado } \\
\text { temporoespacialmente. }\end{array}$ & 6 \\
\hline Biología la vida en la tierra & Problema de TD & $\overline{C o ́ d i g o ~}$ \\
\hline No detectado & No detectado & - \\
\hline
\end{tabular}

En los textos Avanza Ciencias 9 y en el Hipertexto Santillana Ciencias 9 se hallan proposiciones erróneas, descontextualización del tema y conceptos ahistóricos (códigos 3,6 y 9); en el primer texto además se hallaron problemas de TD código 5 es decir, no se mencionan las imágenes incluidas; código 7, no reconoce los trabajos previos que contribuyeron con el desarrollo del modelo; código 10, porque omitió información del modelo; código 12, no cuenta con tareas para reforzar aprendizajes; además el Hipertexto Santillana Ciencias 9, no tiene actividades para detectar los presaberes (código 11); mientras que en el texto de Biología la vida en la tierra no se detectaron problemas de TD, algunos ejemplos de muestran en la tabla 8. 


\section{Discusión}

Un campo disciplinar se caracteriza por la manera particular que comunica la ciencia con un fin educativo. La TD responde a qué saberes se comunican y la LSF al cómo se comunican, están interrelacionadas; los problemas de la LSF pueden afectar la calidad de la TD, la comprensión del tema y generar aprendizajes alternativos. El lenguaje de las ciencias naturales se considera difícil de entender debido a la terminología que junto con la gramática, producen un efecto global en la redacción (palabras y estructuras) a la que se enfrenta el lector; es por eso que el autor debe recurrir a estructuras gramaticales para construir un mensaje dentro de un contexto, con diferentes grados de abstracción en la cultura donde los lectores se encuentran inmersos.

Para analizar el discurso de los textos es importante el análisis gramatical, de acuerdo a Halliday, "un análisis de discurso que no se base en una gramática no es en realidad un análisis en absoluto, sino simplemente un comentario sobre el texto" (citado por Moss, 2013), no obstante, la LSF realiza un análisis multifuncional de los cuales la gramática es solo una de sus partes. Los resultados son analizados desde la perspectiva de Moss sobre la LSF y la teoría de la TD de Chevallad.

Un texto escolar de ciencias naturales debería tener desde la LSF, características que faciliten la comprensión del mensaje que lleva un saber, objeto de TD con fines educativos. En los textos analizados sobre el modelo de la doble hélice del ADN predominan los procesos relacionales sobre los materiales (tabla 3), que son los procesos que transforman el mundo externo, típicos de las ciencias naturales; además hay pocos procesos materiales ergativos (visible el agente responsable) necesarios para una mejor comprensión de procesos; aunque a veces parecen iterativos, son mucho más directos; es decir, los textos analizados tienen un alto nivel de abstracción y su discurso no es el típico de las ciencias naturales; porque según Moss, los procesos relacionales "caracterizan o identifican cosas, actos, fenómenos y hechos más propios de las ciencias sociales que imprimen abstracción y fenómenos estáticos" (2013); y la carencia de un agente causal de los procesos materiales no-ergativos, diluye la responsabilidad.

Las ciencias naturales utilizan la narrativa expositiva, realizan afirmaciones que imprimen certeza y dan poco espacio para la duda; 
es un efecto producido por el uso de verbos en tiempo presente. En los textos Avanza Ciencias 9 e Hipertexto Santillana Ciencias 9, más de la mitad de los verbos utilizados en el discurso están en presente simple como se mostró en la tabla 4, es decir, que la ciencia que comunican es eternizada, estática, terminada y descontextualizada (Gallego, Gallego, \& Pérez, 2010); y a pesar de que mencionen hechos históricos no son referidos en tiempo pasado. Para alfabetizar científicamente, es necesario incluir aspectos relacionados con la evolución del conocimiento científico, producto de una construcción social y cultural acumulativa, que puede cambiar con el tiempo y que desde la epistemología ayuda a contextualizar el proceso de TD; pero ese no es el caso del texto Biología la vida en la tierra, posee la mayoría de los verbos en tiempo pasado y hace un reconocimiento del desarrollo científico como un proceso cultural no autoengendrado.

En los textos científicos el uso de metáforas está dirigido a facilitar que los conceptos sean comprendidos, antes el lenguaje de las ciencias se consideraba preciso, literal, riguroso y referenciado donde las metáforas introducían ambigüedades; actualmente el lenguaje es menos redundante y no se puede prescindir de las metáforas sobretodo en el proceso de didactización cuando en los textos escolares de ciencias naturales se manejan conceptos abstractos. Aunque, así como puede facilitar la comprensión, también se puede correr el riesgo de confundir la metáfora con la realidad y las propiedades y preguntas respecto al objeto de interés terminan reforzando la imagen metafórica (Martín, 2010). El modelo de la doble hélice del ADN siempre ha sido comunicado mediante la metáfora de la escalera y la doble hélice como en la tabla 5, puesto que los conceptos son muy abstractos y de nivel nanoscópico, lo que dificulta su comprensión; y las metáforas presentes en los textos analizados contribuyen a clarificar el modelo sin introducir ambigüedades.

Cada vez la ciencia se vuelve más dinámica y flexible en su comunicación escrita, no solo es menos redundante sino que también aumentó el uso de nominalizaciones, al objetivizar un proceso y sus propiedades se busca inmovilizar la realidad, en la que predominan los objetos y los procesos sirven solo para definir y clasificar, presentan hechos como acabados e incambiable, debe ser aceptado por el lector. Cuando hay muchas nominalizaciones en el texto lleva a altos niveles de abstracción, perdida de información que no es bien reconstruida en el aprendizaje (Moss, 2013); en los textos analizados no son muchas las nominalizaciones halladas que puedan afectar su comprensión en este sentido. 
Una buena TD en los textos escolares no es suficiente para comunicar el saber al lector, se requiere de guiarlo, indicarle su rol, situarlo en el contexto y mostrarle los pasos del desarrollo del contenido; valiéndose de demandas, ofertas o peticiones y de esta manera contribuye a que el estudiante comprenda el tema.

La metafunción interpersonal es la interacción entre el escritor y el lector, es parte importante para comunicar el mensaje enmarcado dentro de un ambiente de complicidad y confianza a través de un dialogo directo para despertar su interés, e involucra al estudiante como parte activa en la reconstrucción del escenario, además guía, intercambia y contextualizar los saberes, para alcanzar aprendizajes significativos; porque según Blanco (2004) "una de las razones que pueden explicar, en parte, la desmotivación de los alumnos es la falta de conexión entre muchos de los contenidos que se enseñan en las clases de ciencia con la realidad que conocen y viven".

El autor de los textos Avanza Ciencias g e Hipertexto Santillana Ciencias 9, interactúa mediante preguntas que inducen respuestas, invitan a reflexionar, desarrollar tareas, tomar decisiones; pero no es una regularidad en todas las partes del texto, porque en la presentación de los conceptos nuevos en el cuerpo del texto no hay ningún tipo de interacción; lo que no ocurre con el texto Biología la vida en la tierra, que emplea preguntas y respuestas a través de un monólogo desarrollado por el autor (tabla 6). La comunicación interpersonal en los textos también se ve afectada por la poca existencia de cláusulas mentales que permitan conocer la experiencia del autor acerca del mundo como su propio "yo dotado de conciencia", llevando al lector a acuerdos o desacuerdos. Es de resaltar que solo el texto Avanza Ciencias 9 dedicó una pregunta específica para sacar los presaberes, importante para que el lector sepa lo que el texto le puede aportar.

En cuanto al proceso de TD que tuvo el modelo de la doble hélice del ADN para ser didactizado, en los textos Avance Ciencias 9 e Hipertexto de Santillana 9, se hallaron varios errores, generalizaciones de conceptos, imprecisiones, actividades que no estimulan los procesos de aprendizaje; existe poco o nada de reconocimiento de otros investigadores que contribuyeron con el desarrollo del modelo y el proceso dinámico y cultural de la ciencia que se ha venido desarrollando; los hallazgos parecen acabados y presentados como verdades irrefutables; presentan una ciencia descontextualizada y ahistórica (Gallego, Gallego, \& Pérez, 
2010). Este modelo fue solo uno más de los descubrimientos logrados con apoyo de diferentes investigadores, que sigue aportando al avance de la ciencia y su aprendizaje es útil en la vida de las personas y su entorno.

\section{Conclusiones}

En los textos escolares de ciencias naturales es importante tanto los saberes que se pretenden enseñar como la comunicación del mensaje, la LSF y la TD actúan de forma complementaria para facilitar la comprensión del texto y cumplir con la función de educar. Muchos de los aspectos problemáticos hallados en el análisis de la LSF coinciden con los de la TD, como el uso de los verbos en presente simple y nominalizaciones que llevan a la descontextualización de la ciencia, y en consecuencia a la falta de interés del estudiante por aprender puesto que la ciencia es presentada sin una epistemología que la muestre como resultado de un proceso de construcción cultural; y conducen a una alfabetización científica pobre, carente de asideros de la ciencia.

Los textos escolares de ciencias naturales van dirigidos a una población específica de estudiantes, requiere de una TD adecuada, lograda con todas las herramientas de la LSF que ayudan a comunicar los saberes de forma comprensible; es el docente el llamado a seleccionar los textos adecuados, hacer la vigilancia epistemológica de los textos y brindar orientación en el momento que los estudiantes presenten dificultades con la comprensión del texto; debido a que las editoriales en nuestro país no se responsabilizan de la problemática generada.

\section{Referencias bibliográficas}

Bermúdez, G. (2014). La transposición del concepto de diversidad biológica. Un estudio sobre los libros de texto de la educación secundaria española. Enseñanza de las Ciencias, 32(3), 285-302.

Blanco, A. (2004). Relaciones entre la educación científica y la divulgación de las ciencias. Revista Eureka sobre Enseñanza y Divulgación de las Ciencias, 1(2), 70-86.

Chamizo, J., \& Gutiérrez, M.Y. (2004). Conceptos fundamentales en química 1. Valencia. Educación Química, 15 (9), 359-365. 
Chamorro, D. M. (2013). El lenguaje para enseñar y aprender las ciencias naturales: Un caso de oportunidades perdidas para la gran formación ciudadana. Revista signos, 46(81), 3-28.

Chargaff, E. (1951). Structure and function of nucleid acid as cells constituents. Fed Proc. 10(3), 654-659.

Chevallard, Y. (1991). La transposición didáctica. Del saber sabio al saber enseñado. Buenos Aires: Aique.

Franklin, R. G. (1953). Evidence for 2-chain helix in crystalline structura of sodium deoxiribonucleate. Nature, 172, 156-157.

Franzolin, F., \& Bizzo, N. (2015). Types of deviation in genetics knowledge presented in textbooks elative to the reference literature. Procedia - Social and Behavioral Sciences, $167,223-228$.

Gallego, A., Gallego, R., \& Pérez, R. (2010). El problema de la recontextualización en la transposición didáctica. Campo Abierto, 29 (2), 63 - 76.

Griffith. (1928). The significance of pneumoccocal types. Journal of Hygiene, 27(2), 11, 113-159.

Halliday, M. (2004). An introduction to functional grammar. Londres: Edward.

Halliday, M. (1994). An introduction to functional grammar. London: Arnold.

Halliday, M. M. (1993). Writing science: literacy and discursive power. Londres: The Falmer Press.

Halliday, M., \& Hasan, R. (1991). Language. contex and text: Aspects of languajein a social semiotic perspective. Oxford: Oxfors University Press.

Herreño, J., Gallego, R., \& Pérez, R. (2010). Transposición didáctica del modelo científico de Lewis-langmuir. Revista Eureka sobre Enseñanza y Divulgación de la Ciencia, 7(2), 527-543.

Hershey, A., \& Chase, M. (1952). Independent functions of viral protein and nucleic acid in growth of bacteriophage. J Gen Physiol, 36;39-56.

López, R. (2012). Análisis de la transposición didáctica del modelo científico para la electroquímica en los textos de enseñanza . Revista Visión Electrónica, 6(1), 53 - 55

Manjarrés, B., \& Chamorro, D. (2011, p. 135). El texto escolar y el aprendizaje. Enredos y desenredos. Barranquilla: Universidad del Norte.

Martin, J., \& Rose, D. (2003). Working with discourse: Meaning beyond the clause. London: Continuum. 
Martin, J., \& White, P. (2005). The languaje of evaluation. Appraisal in English. Basingstoke: Palgrave Macmillan.

Martín, S. (2010). Sobre genes y metáforas científicas. Fragmentos de Filosofía. 8, 121137.

Mendel, G. (1866). Versuche über Planzenhybriden", Verhandlungen des naturforschenden Vereines in Brünn. Abhandlungen: Bd. für das Jahr 1865.

Ministerio de Educación Nacional - MEN. (2004). Estándares básicos de competencias. Bogotá: IPSA.

Moss, G. (2013). Formas de construir conocimiento, transitividad, ergatividad, metafora gramatical y coherencia en textos de ciencias naturales y sociales. Revista de la Facultad de Lenguas de la Benemerita Universidad Autónoma de Puebla, 10, 8-16.

Moss, G. (2011). Un modelo funcional del lenguaje. En N. Manjarrés, \& Chamorro, D., El texto escolar y el aprendizaje: enredos y desenredos. Barranquilla: Universidad del Norte.

Moss, G., Natale, L., \& Oteiza, T. (2009). El lenguaje de los textos escolares, el aprendizaje, la ideología y la formación ciudadana. Revista delta, 25:Especial, 549-753.

Pauling, L., \& Corey, R. B. (1953). A proposed structure for nucleic acids. Proc Natl Acad Sci, 39(2), 84-97.

Pérez, U., Álvarez, M., \& Serrallé, J.F. (2009). Los errores de los libros de texto de primer curso ESO sobre la evolución histórica del conocimiento del universo. Enseñanza de las Ciencias, 27(1), 109-120.

Pozo, J., \& Gómez, M. (1998). Aprender y enseñar ciencia: del conocimiento cotidiano al conocimiento científico. Madrid: Morata.

Raviolo, A. (2008). Las definiciones de conceptos químicos básicos en textos de secundaria. Educación Química, 19(4), 315-322.

Raviolo, A. (2009). Modelos, analogías y metáforas en la enseñanza de la química. Educación Química, 20(1), 55 - 60.

Totorikaguena, L. (2013). Los errores conceptuales y las ideas previas del alumnado de ciencias en el ámbito de la enseñanza de la biología celular. Propuestas alternativas para el cambio conceptual. Disponible en: https://addi.ehu.es/bitstream/10810/10625/1/ GRAL.LideTotorikaguena.pdf

Watson, J., \& Crick, F.H.C. (1953). Molecular structure of nucleic acids. Nature, 4356, 737-738. 